\title{
Usulan Perbaikan Proses Pencampuran Powder Jelly Dengan Metode Failure Mode and Effect Analysis (FMEA) Dan Pengurangan Waktu Proses di Pabrik Pangan
}

\author{
Heris Muhamar ${ }^{1}$, Hery Hamdi Azwir ${ }^{2}$ \\ 1) Faculty of Engineering, Industrial Engineering Department, President University \\ Jl. Ki Hajar Dewantara \\ Kota Jababeka,Cikarang, Bekasi - Indonesia 17550 \\ Email: ${ }^{1}$ herizzmuhamar96@gmail.com, ${ }^{2}$ hery.azwir@president.ac.id
}

\begin{abstract}
Abstrak
Pabrik pangan adalah perusahaan trading kimia dan pengolahan bahan pangan setengah jadi. Salah satu olahan pangan yang diproduksi adalah jelly powder. Adapun permasalahan yang dihadapi oleh pabrik pangan adalah bagaimana mengurangi terjadinya cacat produk dan lamanya proses pencampuran produk yakni 180 menit untuk type jelly A - 147. Usulan perbaikan dilakukan dengan metode Failure Mode and Effect Analysis (FMEA) dimana produk cacat terjadi paling banyak diparameter hardness dan syneresis dan diakibatkan oleh 4 elemen yakni Metode, Lingkungan, Manusia, dan material. Pada usulan perbaikan ini dilakukan penambahan metode dengan adanya penimbangan ulang setelah bahan baku di grinding (haluskan) karena pada proses ini bahan baku additive yang berdifat free flowing akan berkurang karena terkena udara, ditambahkannya alat pengontrol suhu diarea bahan baku, dilakukannya training tentang bahan baku, dan pencarian supplier baru dengann spesifikasi yang sama. Pada pengurangan waktu proses didapatkan waktu mixing 150 menit, sehingga pabrik pangan bisa mengurangi waktu mixing selama 30 menit.
\end{abstract}

Kata kunci : FMEA, pengurangan waktu, cacat, kualitas.

\section{Abstract}

Food factory is a chemical trading and processing company for semi-finished food. One of the processed foods produced is jelly powder. The problems faced by food manufacturers are how to reduce the occurrence of product defects and the length of product mixing process that is 180 minutes for A-type 147 jelly. Proposed improvements are made by the Failure Mode and Effect Analysis (FMEA) method where defective products occur at most hardness and syneresis parameters and are caused by 4 elements namely method, environment, human, and material. In this proposed improvement, additional methods are carried out by reconsideration after the raw material is grinding (puree) because in this process additive raw materials which are free flowing will be reduced due to exposure to air, added temperature control devices in raw materials, training on raw materials, and search for new suppliers with the same specifications. At the reduction of processing time, the mixing time is 150 minutes, so the food factory can reduce the mixing time by 30 minutes.

Keywords: FMEA, reduction of processing time, Defect, Quality

\section{Pendahuluan}

Pabrik Pangan merupakan perusahaan yang bergerak di bidang trading bahan tambahan pangan dan pengolahan pangan. Salah satu produk pengolahan pangan unggulan yang dihasilkan yaitu jelly powder. Produk jelly powder yang diproduksi oleh Pabrik Pangan dipakai oleh produsen industri pangan (minuman dan makanan) besar di Indonesia. Jelly Powder adalah makanan rendah kalori dan bertekstur kenyal dengan campuran dari karaginan dan tepung konyaku serta bahan tambahan pangan lainnya. Campuran karaginan dan tepung konyaku bersifat sinergi dalam memproduksi gel dengan kekuatan tinggi, tekstur yang baik dan elastis, serta sinergisnya rendah. Efek sinergis merupakan yang sangat penting dalam pemanfaatan campuran karaginan dan tepung konyaku.

Permasalahan yang masih dihadapi oleh Pabrik Pangan adalah Syneresis dan Hardness. Sineresis adalah peristiwa keluarnya air dalam gel dimana gel mengkerut sehingga cenderung memeras air 
keluar dari dalam sel (Boca Raton, 1983). Produk gel yang di simpan pada suhu rendah seperti puding dan jeli memerlukan sifat kekuatan gel tinggi dan sineresis rendah. Sineresis yang tinggi pada produk gel akan menyebabkan gel menjadi mengkerut atau kering selama penyimpanan. Kekuatan pada gel puding atau jeli mempunyai pengaruh terhadap tingkat penerimaan konsumen. Puding atau jeli yang mempunyai kekuatan gel yang rendah akan mengakibatkan puding atau jeli menjadi lembek sehingga bisa mengakibatkan penerimaan konsumen menjadi menurun. Sedangkan Hardness merupakan sifat yang berhubungan dengan gaya yang digunakan untuk menekan produk makanan padat antara gigi geraham atau antara makanan semi solid antara lidah dan langit - langit mulut. Hardness juga dapat diartikan tingkat kekerasan bahan pangan yang ditentukan dengan kemudahan atau tidaknya untuk digigit. Pabrik Pangan mendapatkan keluhan pelanggan sebanyak 10 untuk type jelly A - 147 dari Jul 2016 - Jun 2017 dengan catatan keluhan pelanggan yaitu keterlambatan pengiriman pada saat pembelian dikarenakan banyaknya permintaan produksi dari customer sehingga Pabrik Pangan kadang melakukan penundaan produksi bagi customer yang tidak dipioritaskan atau pembelian di bawah $250 \mathrm{~kg}$. Oleh karena itu, analisis pengurangan waktu proses mixing di produksi juga perlu dilakukan pada Pabrik Pangan agar proses delivery lebih cepat karena proses pencampuran jelly powder sebelumnya membutuhkan 180 menit.

\section{Metode Penelitian}

\subsection{Observasi Awal}

Observasi awal dilakukan dengan wawancara tanya jawab secara langsung kepada Supervisor laboratorium Quality Control dan Supervisor Produksi Pabrik Pangan.

\subsection{Identifikasi Masalah}

Setelah dilakukan observasi secara langsung, dilakukan identifikasi masalah menggunakan diagram pareto. Fungsi diagram pareto adalah untuk mengidentifikasi atau menyeleksi masalah utama untuk peningkatan kualitas dari yang paling besar ke yang paling kecil (Zulian, 2001). Diagram pareto menampilkan suatu urutan grafik batang berdasarkan klasifikasi data permasalahan dimulai dari bagian kiri yang menunjukkan urutan rangking tertinggi, hingga ke bagian kanan yang menunjukkan urutan rangking yang paling rendah. Setelah diidentifikasi diperoleh adanya permasalahan utama yaitu banyaknya sisa fase gerak yang terbuang.

\subsection{Pengumpulan Data}

Selanjutnya, melakukan pengumpulan data produksi dan data reject serta melakukan analisis waktu produksi Jelly Powder sehingga mendapatkan waktu produksi yang maximal. Didalam pengumpulan data diperlukan metode yang tepat untuk mendapatkan data - data yang akurat. Ada 2 metode yang dapat digunakan yaitu dengan menggunakan data primer dan data sekunder, yaitu:

a. Data Primer

Adalah metode untuk mendapatkan data langsung dari sumber penelitian yaitu Pabrik Pangan. Selain dengan melakukan pengamatan langsung diperusahaan, data juga diperoleh dengan melakukan wawancara pada kepala bagian QC, PPIC dan Produksi.

\section{b. Data Sekunder}

Data Sekunder diperoleh dari sumber - sumber tertulis yang berhubungan dengan topik masalah yang akan diselesaikan. Data sekunder diperoleh dari laporan hasil pengecekan

Setelah data sudah terkumpul, maka langkah selanjutnya mengelola data dan menentukan perbaikan dengan QC seven tools dan metode Menejemen resiko yaitu Failure Mode and Effect Analysis. Sedangkan untuk uji waktu maximum mixing produksi melakukan uji annova - one way dengan analisis di 3 waktu yaitu 90 menit, 120 menit dan 150 menit. 


\subsection{Analisis Data dan Perbaikan}

Setelah diketahui permasalah utama, kemudian dicari akar dari permasalahan yang paling sering terjadi menggunakan diagram fishbone. Kemudian, dilakukan analisis $5 \mathrm{~W}+1 \mathrm{H}$ untuk mencari tahu permasalahan yang terjadi secara detail berupa pertanyaan yaitu: what, who, where, when, why, dan how (apa, siapa, dimana, kapan, mengapa, dan bagaimana). Setelah itu dilakukan Failure Mode and Effect Analysis (FMEA) yaitu sebuah teknik yang digunakan untuk mengidentifikasi dan mengeleminasi potential failure, masalah eror dari sebuah sistem, desain, proses, dan servis sebelum produk itu sampai ditangan customer (Susanto dan Rahardjo, 2013).

Sedangkan untuk pengujian data sample waktu mixing dilakukan dengan metode Anova - One Way. Interaksi kesamaan antara fakor - faktor dalam mempengaruhi variabel independen, dengan sendirinya telah dieleminasi. Jika interaksi artinya efek salah satu faktor pada variabel dependen memiliki garis yang tidak sejajar dengan pengaruh faktor lainnya, pada variabel pararel dependen, maka tidak ada interaksi antar faktor (Supratman dan Herlina, 2017).

\section{Hasil dan Pembahasan}

\subsection{Identifikasi dan Stratifikasi Masalah}

Berdasarkan proses observasi diperoleh diperoleh data reject periode Jul 2015 - Jun 2017 dan data keluhan pelanggan untuk jelly powder A - 147 Jul 2016 - Jun 2017. Data tersebut diperoleh dari data QC dan data Marketing Pabrik pangan.Berikut adalah data reject jelly powder semua type dipabrik pangan dan keluhan pelanggan.

Tabel 1. Data keluhan pelanggan Type Jelly A - 147 Jul 2016 - Jun 2017

\begin{tabular}{|c|c|c|}
\hline No & Keluhan Keterlambatan pengiriman & Total \\
\hline 1 & CV. XYZ 1 & 2 \\
\hline 2 & CV. XYZ 2 & 2 \\
\hline 3 & CV. XYZ 3 & 1 \\
\hline 4 & CV. XYZ 4 & 4 \\
\hline 5 & CV. XYZ 5 & 1 \\
\hline
\end{tabular}

Tabel 2. Data Produk Reject Periode Juli 2015 - Juni 20117

\begin{tabular}{|c|c|c|c|c|c|c|c|}
\hline \multirow[b]{2}{*}{ Periode } & \multirow[b]{2}{*}{$\begin{array}{l}\text { Jumlah Produksi } \\
\text { (batch) }\end{array}$} & \multicolumn{5}{|c|}{ Cacat } & \multirow[b]{2}{*}{$\begin{array}{c}\text { Jumlah } \\
\text { Cacat }\end{array}$} \\
\hline & & 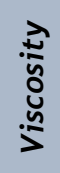 & $\frac{\overrightarrow{0}}{\frac{0}{0}}$ & 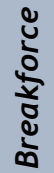 & $\begin{array}{l}\tilde{y} \\
\frac{\tilde{d}}{\delta} \\
\frac{0}{1}\end{array}$ & 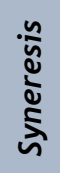 & \\
\hline Jul -15 & 730 & 1 & 0 & 0 & 2 & 3 & 6 \\
\hline Aug-15 & 517 & 1 & 0 & 0 & 1 & 2 & 4 \\
\hline Sep-15 & 738 & 0 & 0 & 1 & 2 & 3 & 6 \\
\hline Oct-15 & 630 & 0 & 1 & 0 & 3 & 1 & 5 \\
\hline Nov-15 & 723 & 1 & 1 & 0 & 1 & 3 & 6 \\
\hline Des-15 & 630 & 0 & 1 & 0 & 2 & 2 & 5 \\
\hline Jan-16 & 705 & 0 & 0 & 1 & 2 & 3 & 6 \\
\hline Feb-16 & 643 & 0 & 1 & 0 & 2 & 2 & 5 \\
\hline Mar-16 & 635 & 1 & 0 & 0 & 1 & 3 & 5 \\
\hline Apr-16 & 720 & 0 & 0 & 1 & 2 & 3 & 6 \\
\hline May-16 & 625 & 0 & 1 & 0 & 2 & 2 & 5 \\
\hline Jun-16 & 642 & 1 & 0 & 0 & 1 & 3 & 5 \\
\hline Jul-16 & 597 & 0 & 1 & 0 & 1 & 3 & 5 \\
\hline Aug-16 & 518 & 1 & 0 & 0 & 1 & 2 & 4 \\
\hline Sep-16 & 613 & 1 & 0 & 0 & 3 & 1 & 5 \\
\hline Oct-16 & 704 & 0 & 1 & 0 & 3 & 2 & 6 \\
\hline Nov-16 & 610 & 1 & 0 & 0 & 2 & 2 & 5 \\
\hline
\end{tabular}


Tabel 2. Data Produk Reject Periode Juli 2015 - Juni 20117 (lanjuitan)

\begin{tabular}{|c|c|c|c|c|c|c|c|}
\hline \multirow[b]{2}{*}{ Periode } & \multirow[b]{2}{*}{$\begin{array}{l}\text { Jumlah Produksi } \\
\text { (batch) }\end{array}$} & \multicolumn{5}{|c|}{ Cacat } & \multirow[b]{2}{*}{$\begin{array}{c}\text { Jumlah } \\
\text { Cacat }\end{array}$} \\
\hline & & 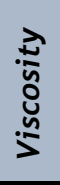 & $\frac{\overrightarrow{0}}{\frac{0}{0}}$ & 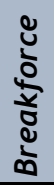 & 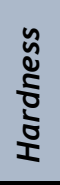 & $\frac{\frac{n}{\tilde{n}}}{\frac{d}{5}}$ & \\
\hline Oct-16 & 704 & 0 & 1 & 0 & 3 & 2 & 6 \\
\hline Nov-16 & 610 & 1 & 0 & 0 & 2 & 2 & 5 \\
\hline Des-16 & 716 & 0 & 1 & 0 & 3 & 2 & 6 \\
\hline Jan-17 & 725 & 0 & 1 & 0 & 2 & 3 & 6 \\
\hline Feb-17 & 519 & 0 & 0 & 1 & 1 & 2 & 4 \\
\hline Mar-17 & 725 & 1 & 0 & 0 & 3 & 2 & 6 \\
\hline Apr-17 & 590 & 0 & 0 & 0 & 2 & 3 & 5 \\
\hline Mei-17 & 630 & 0 & 0 & 1 & 2 & 2 & 5 \\
\hline Jun-17 & 724 & 1 & 0 & 0 & 2 & 3 & 6 \\
\hline Total & 15609 & 10 & 9 & 5 & 46 & 57 & 127 \\
\hline
\end{tabular}

Berdasarkan Tabel 2, keluhan pelanggan tersebut maka pabrik pangan mengusulkan untuk mencari proses waktu produksi yang paling minimal untuk pencampuran proses jelly powder sedangkan pada tabel 5 pabrik pangan melakukan perbaikan menggunakan metode Failure Mode and Effect Analysis (FMEA).

Tabel 3. Stratifikasi Kegagalan Proses Proses Produksi Jelly Powder Jul 2015 - Jun 2017

\begin{tabular}{|c|c|c|c|c|c|}
\hline No. & $\begin{array}{c}\text { Moda kegagalan (out of } \\
\text { spec) }\end{array}$ & $\begin{array}{l}\text { Frekuensi } \\
\text { (batch) }\end{array}$ & $\begin{array}{c}\% \\
\text { Dari Total }\end{array}$ & $\begin{array}{l}\text { Frekuensi } \\
\text { Komulatif }\end{array}$ & $\begin{array}{c}\% \\
\text { Komulatif }\end{array}$ \\
\hline 1 & Syneresis & 57 & 44,88 & 57 & 44,88 \\
\hline 2 & Hardness & 46 & 36,22 & 103 & 81,10 \\
\hline 3 & Viscosity & 10 & 7,87 & 113 & 88,98 \\
\hline 4 & Rigidity & 9 & 7,09 & 122 & 96,06 \\
\hline 5 & Breakforce & 5 & 3,94 & 127 & 100,00 \\
\hline & Total & 127 & & & \\
\hline
\end{tabular}

Berdasarkan Tabel 3, diketahui bahwa moda kegagalan atau reject yang banyak terdiri dari Syneresis dan Hardness. Gambar 1 adalah diagram pareto kegagalan yang terjadi di pabrik pangan ini.

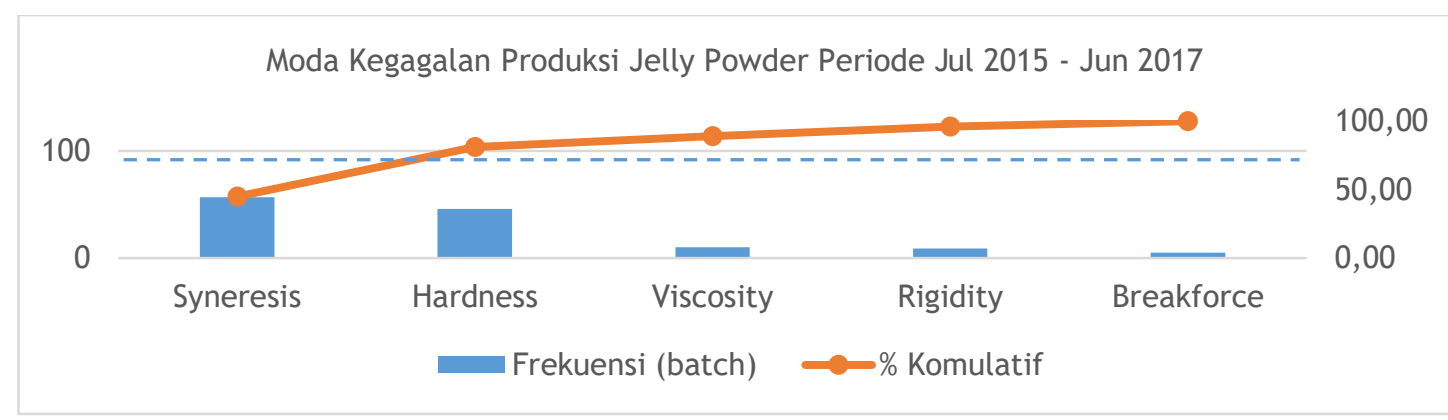

Gambar 1. Diagram Pareto moda kegagalan jelly powder jul 2015 - jun 2017. 


\subsection{Penentuan Sebab Akibat}

Setelah mengetahui permasalahan yang sedang dihadapi, maka selanjutnya dibuat diagram sebab - akibat untuk mencari akar dari permasalahan. Berikut adalah diagram sebab akibat untuk dua moda kegagalan yaiyu Syneresis dan Hardness :

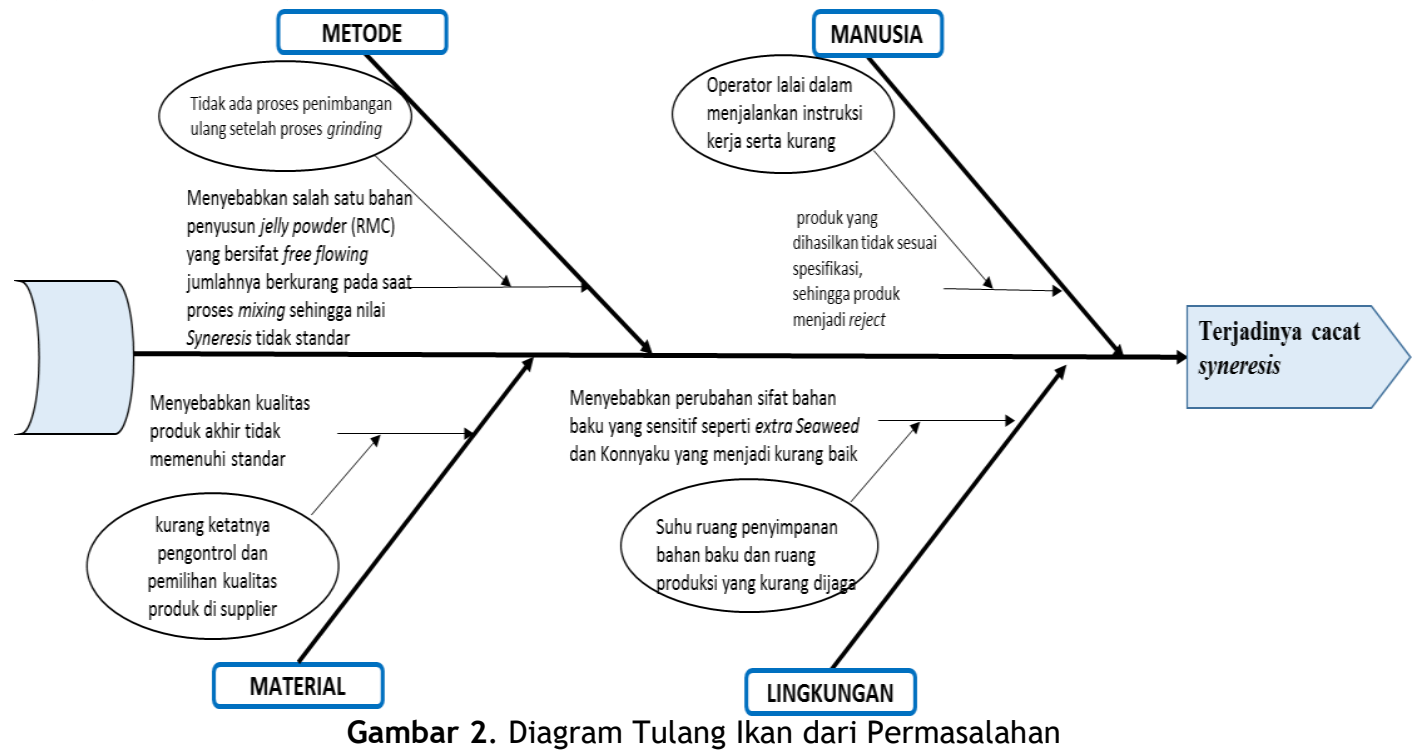

Pembuatan Fishbone atau diagram sebab akibat ini bertujuan agar faktor - faktor penyebab dan karakterisktik kualitas yang di sebebkan oleh faktor - faktor penyebab dapat teridentifikasi. Menggunakan 4 faktor dalam pembuatan diagram penyebab akibat yaitu :

a. Faktor Lingkungan pada diagram sebab dan akibat ini dikarenakan oleh suhu ruang penyimpanan bahan baku dan ruangan produksi yang kurang di jaga dan di kontrol sehingga menyebabkan perubahan sifat bahan baku yang sensitif dengan suhu seperti ekstra rumput laut dan tepung konyaku, sehingga bahan baku tersebut masih bagus kualitasnya ketika hendak akan di produksi.

b. Faktor Manusia digunakan untuk mengidentifikasi personil - peronil yang terlibat pada proses persiapan dan proses sampling. Pada faktor ini operator gudang lalai dalam menjalankan instruksi kerja serta kurang pemahaman akan kode bahan baku sehingga bahan baku yang mempunyai sifat fisik yang sama seperti tepung konyaku dan ekstra rumput laut menjadi tertukar sehingga mengakibatkan produk menjadi reject.

c. Faktor method digunakan untuk mengidentifikasi metode pada proses produksi jelly Powder. Faktor metode dalam diagram sebab dan akibat ini mengakibatkan bahan baku yang bersifat free flowing jumlahnya berkurang karena teroksidasi atau terkena udara, sehingga harus ada penimbangan ulang bahan baku setelah proses grinding atau penghalusan, atau dengan menambahkan treatment agar bahan baku tersebut tidak mudah teroksidasi.

d. Faktor Material digunakan untuk mengidentifikasi material yang digunakan pada produksi. Pada faktor ini peneimaan bahan baku kurang ketat dan pengontrolan sehingga bahan baku akan di terima walaupun spesifikasi mendekati batas kendali atas dan bawah di Pabrik Pangan sehingga harus menambahkan pilihan supplier agar spesifikasi bahan baku bisa berada dalam batas kendali, selain melakukan pemilihan supplier dengan ketat Pabrik Pangan juga harus melakuakn Pre-Shipment Sample (PSS) kepada supplier agar mendapatkan bahan baku yang sama saat pembelian.

\subsection{Analisis dan Perbaikan}

\subsubsection{Analisis $5 W+1 H$}

Setelah dilakukan penguraian masalah dengan diagram sebab dan akibat, maka dapat diketahui faktor - faktor mana saja yang menyebabkan moda kegagalan tersebut. Untuk memperjelas pemecahan akar masalah yang telah didapat pada diagram Fishbone maka dilakukan analisa 5W + $1 \mathrm{H}$, dari tabel analisa $5 \mathrm{~W}+1 \mathrm{H}$ dapat diketahui jalan keluar tersebut nantinya akan berkesinambungan 
dalam proses peningkatan kualitas produk di Pabrik Pangan. berikut adalah tabel $5 \mathrm{~W}+1 \mathrm{H}$ di Pabrik Pangan.

'Tabel 4. Analisis $5 \mathrm{~W}+1 \mathrm{H}$ Kegagalan Proses Jelly Powder

\begin{tabular}{|c|c|c|c|c|c|c|c|}
\hline FAKTOR & MASALAH & WHY & WHAT & WHERE & WHEN & WHO & HOW \\
\hline Metode & $\begin{array}{c}\text { Tidak ada } \\
\text { proses } \\
\text { penimbangan } \\
\text { ulang setelah } \\
\text { proses } \\
\text { grinding }\end{array}$ & $\begin{array}{l}\text { Menyebabkan } \\
\text { salah satu } \\
\text { bahan } \\
\text { penyusun jelly } \\
\text { powder (RMCl) } \\
\text { yang bersifat } \\
\text { free flowing } \\
\text { jumlahnya } \\
\text { berkurang } \\
\text { pada saat } \\
\text { proses mixing } \\
\text { sehingga nilai } \\
\text { hardness tidak } \\
\text { standar } \\
\end{array}$ & $\begin{array}{c}\text { Menambahkan } \\
\text { instruksi kerja } \\
\text { penimbangan } \\
\text { pada SOP } \\
\text { kerja/flow } \\
\text { chart proses } \\
\text { produksi }\end{array}$ & $\begin{array}{c}\text { Divisi } \\
\text { Produksi }\end{array}$ & $\begin{array}{l}\text { Perbaik } \\
\text { an } \\
\text { segera }\end{array}$ & $\begin{array}{l}\text { Manajer } \\
\text { Produksi }\end{array}$ & $\begin{array}{c}\text { Melakukan } \\
\text { perbaikan dengan } \\
\text { cara menambahkan } \\
\text { proses } \\
\text { penimbangan ulang } \\
\text { setelah proses } \\
\text { grinding (sebelum } \\
\text { proses mixing) } \\
\text { pada SOP kerja }\end{array}$ \\
\hline Lingkungan & $\begin{array}{c}\text { Suhu ruang } \\
\text { penyimpanan } \\
\text { bahan baku } \\
\text { dan ruang } \\
\text { produksi yang } \\
\text { kurang } \\
\text { dikontrol }\end{array}$ & $\begin{array}{l}\text { Menyebabkan } \\
\text { perubahan } \\
\text { sifat bahan } \\
\text { baku yang } \\
\text { sensitif seperti } \\
\text { konjac dan } \\
\text { karagenan } \\
\text { yang menjadi } \\
\text { kurang baik } \\
\text { (nilai hardness } \\
\text { yang tidak } \\
\text { standar) }\end{array}$ & $\begin{array}{l}\text { Diberikan AC } \\
\text { pada ruang } \\
\text { produksi dan } \\
\text { juga ruang } \\
\text { penyimpanan } \\
\text { bahan baku }\end{array}$ & $\begin{array}{c}\text { Gudang } \\
\text { dan ruang } \\
\text { produksi }\end{array}$ & $\begin{array}{l}\text { Perbaik } \\
\text { an } \\
\text { segera }\end{array}$ & $\begin{array}{l}\text { Manajer } \\
\text { Produksi } \\
\text { dan } \\
\text { Mainten } \\
\text { ance }\end{array}$ & $\begin{array}{c}\text { Melakukan } \\
\text { perbaikan dengan } \\
\text { cara penambahan } \\
\text { AC di ruang } \\
\text { produksi gudang } \\
\text { penyimpanan agar } \\
\text { suhu sesuai dengan } \\
\text { spesifikasi yaitu } \\
\text { maksimal } 23^{\circ} \mathrm{C} \text { dan } \\
\text { juga menambahkan } \\
\text { thermohygrometer } \\
\text { pada dinding } \\
\text { ruangan tersebut } \\
\text { agar suhu dapat } \\
\text { terpantau }\end{array}$ \\
\hline Manusia & $\begin{array}{l}\text { Operator } \\
\text { tidak fokus } \\
\text { dalam } \\
\text { menjalankan } \\
\text { Standard } \\
\text { operation } \\
\text { procedur }\end{array}$ & $\begin{array}{c}\text { Menyebabkan } \\
\text { produk yang } \\
\text { dihasilkan } \\
\text { tidak sesaui } \\
\text { standar, } \\
\text { seperti salah } \\
\text { menimbang } \\
\text { material } \\
\text { sehingga jenis } \\
\text { material } \\
\text { tertukar } \\
\end{array}$ & $\begin{array}{l}\text { Pencegahan } \\
\text { dengan } \\
\text { membuat } \\
\text { display } \\
\text { peringatan, } \\
\text { SOP kerja } \\
\text { setiap dinding } \\
\text { ruangan } \\
\text { produksi }\end{array}$ & $\begin{array}{c}\text { Dep. } \\
\text { Produksi }\end{array}$ & $\begin{array}{l}\text { Perbaik } \\
\text { an / } \\
\text { Pencega } \\
\text { han } \\
\text { segera }\end{array}$ & $\begin{array}{l}\text { Menejer } \\
\text { Produksi }\end{array}$ & $\begin{array}{c}\text { Melakukan training } \\
\text { tentang } \\
\text { pengkodean atau } \\
\text { sifat bahan baku } \\
\text { yang hampir sama } \\
\text { sehingga operator } \\
\text { bisa sadar akan } \\
\text { kesalahan tertuker } \\
\text { bahan baku }\end{array}$ \\
\hline Material & $\begin{array}{c}\text { Kualitas } \\
\text { bahan baku } \\
\text { tidak stabil } \\
\text { dari supplier }\end{array}$ & $\begin{array}{l}\text { Menyebabkan } \\
\text { kualitas } \\
\text { produk tidak } \\
\text { memenuhi } \\
\text { standar }\end{array}$ & $\begin{array}{l}\text { Mengkomunikas } \\
\text { ikan masalah } \\
\text { tetang standar } \\
\text { penerimaan } \\
\text { bahan baku } \\
\text { kita ke supplier }\end{array}$ & \begin{tabular}{|} 
Dep. \\
Purchasin \\
g dan \\
Dep. \\
Technical
\end{tabular} & $\begin{array}{l}\text { Perbaik } \\
\text { an / } \\
\text { Pencega } \\
\text { han } \\
\text { segera }\end{array}$ & $\begin{array}{l}\text { Menejer } \\
\text { Purchasi } \\
\text { ng dan } \\
\text { Menejer } \\
\text { teknikal }\end{array}$ & $\begin{array}{c}\text { Mencari supplier } \\
\text { cadangan dengan } \\
\text { kualitas bahan } \\
\text { baku yang baik } \\
\text { serta meminta } \\
\text { Preshipment } \\
\text { sample untuk di } \\
\text { tes oleh QC } \\
\text { sebelum bahan } \\
\text { baku datang ke } \\
\text { gudang / sebelum } \\
\text { pembelian }\end{array}$ \\
\hline
\end{tabular}




\subsubsection{Analisis Failure Mode and Effect Analysis (FMEA)}

Penilaian pada tabel diatas didapatkan dari penilaian yang telah di tetapkan oleh para anggota TIM FMEA di PABRIK PANGAN. Berikut adalah penilaian yang telah ditetapkan untuk nilai severety, occurance, dan detection, yang ditunjukkan dalam Tabel 5.

Tabel 5. Hasil FMEA Proses Produksi Jelly Powder

\begin{tabular}{|l|l|l|c|l|c|}
\hline \multicolumn{1}{|c|}{ PROSES } & $\begin{array}{c}\text { MODA } \\
\text { KEGAGALAN } \\
\text { POTENSIAL }\end{array}$ & $\begin{array}{l}\text { AKTUAL } \\
\text { POTENSIAL DARI } \\
\text { KEGAGALAN }\end{array}$ & $\begin{array}{c}\text { SEVE- } \\
\text { RITY }\end{array}$ & $\begin{array}{l}\text { PENYEBAB } \\
\text { POTENSIAL DARI } \\
\text { KEGAGALAN }\end{array}$ & $\begin{array}{c}\text { OCCU- } \\
\text { RANCE }\end{array}$ \\
\hline $\begin{array}{l}\text { Penimbangan } \\
\text { (setelah } \\
\text { proses } \\
\text { grinding) }\end{array}$ & $\begin{array}{l}\text { Nilai hardness } \\
\text { tidak standar }\end{array}$ & $\begin{array}{l}\text { Produk memiliki } \\
\text { tekstur yang } \\
\text { kurang kokoh }\end{array}$ & 5 & $\begin{array}{l}\text { Tidak ada proses } \\
\text { penimbangan } \\
\text { ulang material } \\
\text { setelah melalui } \\
\text { proses grinding } \\
\text { yang menjadikan } \\
\text { bahan baku } \\
\text { bersifat free } \\
\text { flowing } \\
\text { berkurang } \\
\text { beratnya }\end{array}$ & 5 \\
\hline $\begin{array}{l}\text { Peyimpanan } \\
\text { dan mixing }\end{array}$ & $\begin{array}{l}\text { Nilai hardness } \\
\text { tidak standar }\end{array}$ & $\begin{array}{l}\text { Produk memiliki } \\
\text { tekstur yang } \\
\text { kurang kokoh }\end{array}$ & 7 & $\begin{array}{l}\text { Suhu ruang } \\
\text { penyimpanan } \\
\text { bahan baku dan } \\
\text { ruang produksi } \\
\text { yang kurang } \\
\text { dijaga }\end{array}$ & 5 \\
\hline $\begin{array}{l}\text { Penimbangan } \\
\text { Bahan Formula }\end{array}$ & $\begin{array}{l}\text { Nilai Syneresis } \\
\text { tidak standar }\end{array}$ & $\begin{array}{l}\text { Produk memiliki } \\
\text { kadar air yang } \\
\text { tinggi. }\end{array}$ & 8 & $\begin{array}{l}\text { Operator lalai } \\
\text { dalam } \\
\text { menjalankan } \\
\text { instruksi kerja } \\
\text { (sering tertukar } \\
\text { Konyaku dan } \\
\text { extra seaweed })\end{array}$ & 5 \\
\hline $\begin{array}{l}\text { Penerimaan } \\
\text { Bahan Baku }\end{array}$ & $\begin{array}{l}\text { Nilai Syneresis } \\
\text { yang tidak } \\
\text { standar }\end{array}$ & $\begin{array}{l}\text { Produk memiliki } \\
\text { kadar air yang } \\
\text { cukup tinggi }\end{array}$ & 3 & $\begin{array}{l}\text { Kung ketatnya } \\
\text { kengontrolan } \\
\text { kualitas } \\
\text { tertutma Extra } \\
\text { Seaweed) dari } \\
\text { supplier }\end{array}$ & 5 \\
\hline
\end{tabular}


Tabel 5. Hasil FMEA Proses Produksi Jelly Powder (lanjutan)

\begin{tabular}{|c|c|c|c|c|c|}
\hline PROSES & $\begin{array}{l}\text { PENGENDALIAN } \\
\text { SAAT INI }\end{array}$ & $\begin{array}{l}\text { DETEC- } \\
\text { TION }\end{array}$ & $R P N$ & $\begin{array}{l}\text { TINDAKAN YANG } \\
\text { DIREKOMENDASIKAN }\end{array}$ & $\begin{array}{c}\text { PENANGGUNG } \\
\text { JAWAB DAN TARGET } \\
\text { PENYELESAIAN }\end{array}$ \\
\hline $\begin{array}{l}\text { Penimbangan } \\
\text { (setelah } \\
\text { proses } \\
\text { grinding) }\end{array}$ & $\begin{array}{l}\text { Penimbangan } \\
\text { hasil produk } \\
\text { akhir belum } \\
\text { cukup untuk } \\
\text { mendeteksi } \\
\text { kekurangan } \\
\text { penimbangan }\end{array}$ & 5 & 125 & $\begin{array}{l}\text { Melakukan perbaikan } \\
\text { dengan cara } \\
\text { menambahkan proses } \\
\text { penimbangan ulang } \\
\text { setelah proses grinding } \\
\text { (sebelum proses mixing) } \\
\text { pada SOP kerja }\end{array}$ & $\begin{array}{l}\text { Manager Produksi, } \\
\text { dan Manager } \\
\text { Teknikal } \\
\text { November } 2017\end{array}$ \\
\hline $\begin{array}{l}\text { Peyimpanan } \\
\text { dan mixing }\end{array}$ & $\begin{array}{l}\text { Sudah ada AC } \\
\text { tetapi terbatas, } \\
\text { suhu belum } \\
\text { sesuai dengan } \\
\text { yang } \\
\text { dipersyaratkan }\end{array}$ & 5 & 175 & $\begin{array}{l}\text { Melakukan perbaikan } \\
\text { dengan cara penambahan } \\
\text { AC di ruang produksi } \\
\text { gudang penyimpanan agar } \\
\text { suhu sesuai dengan } \\
\text { spesifikasi yaitu maksimal } \\
23^{\circ} \mathrm{C} \text { dan juga } \\
\text { menambahkan } \\
\text { thermohygrometer pada } \\
\text { dinding ruangan tersebut } \\
\text { agar suhu dapat } \\
\text { terpantau }\end{array}$ & $\begin{array}{l}\text { Manajer Produksi } \\
\text { dan Maintenance } \\
\text { November } 2017\end{array}$ \\
\hline $\begin{array}{l}\text { Penimbangan } \\
\text { Bahan Formula }\end{array}$ & Belum ada & 5 & 200 & $\begin{array}{l}\text { Melakukan Briefing } \\
\text { sebelum elakukan } \\
\text { pekerjaan, mengakan } \\
\text { training untuk operator } \\
\text { produksi tentang } \\
\text { pemahaman dan kualitas } \\
\text { produk serta membuat } \\
\text { display peringatan dan } \\
\text { SOP kerja didinding ruang } \\
\text { produksi }\end{array}$ & $\begin{array}{l}\text { Manager Produksi } \\
\text { dan Manajer } \\
\text { personalia } \\
\text { November } 2017 \\
\text { secara berkala min } \\
6 \text { bulan sekali }\end{array}$ \\
\hline $\begin{array}{l}\text { Penerimaan } \\
\text { Bahan Baku }\end{array}$ & $\begin{array}{l}\text { Pengecekan } \\
\text { awal dilakukan } \\
\text { setelah } \\
\text { penerimaan } \\
\text { barang }\end{array}$ & 5 & 75 & $\begin{array}{l}\text { Mencari supplier } \\
\text { cadangan dengan kualitas } \\
\text { bahan baku yang bagus } \\
\text { dan stabil serta meminta } \\
\text { preshipment sample } \\
\text { untuk dites didivisi QC } \\
\text { sebelum bahan baku } \\
\text { tersebt di beli atau } \\
\text { datang }\end{array}$ & $\begin{array}{l}\text { Manajer purchasing } \\
\text { dan manajer } \\
\text { teknikal November } \\
2017\end{array}$ \\
\hline
\end{tabular}




\subsubsection{Uji Waktu Optimun Proses pencampuran Jelly Powder A - 147}

Data perbaikan ini adalah data dari hasil keluhan pelanggan yang diperoleh oleh pabrik pangan selama satu tahu, dilakukan uji waktu optimun ini dikarekan untuk type jelly powder A - 147 mengalami peningkatan selam asatu tahunnya, dikarenakan aplikasi yang banyak dan harg aynag murah, sehngga perlu dilakukan pengujian waktu minimum untuk mengurangi waktu produksi pencapuranjelly powder A - 147 dipabrik pangan. Pengambilan sampel dilakukan pada satu titik saja. Berikut adalah data pengujian sampel yang dilakukan pada menit ke 90, 120 dan 150 dari waktu standar pencampuran yaitu 180 menit :

Tabel 6. Hasil Analisis Proses Pencampuran Jelly Powder A - 147

\begin{tabular}{|c|c|c|c|c|c|}
\hline Viscositas & Breakforce & Hardness & Rigidity & Sineresis & $\begin{array}{c}\text { Waktu } \\
\text { Pencampuran }\end{array}$ \\
\hline 25 & 120 & 850 & 16 & 6,2 & 90 \\
\hline 21 & 140 & 900 & 18 & 7 & 90 \\
\hline 23 & 200 & 875 & 15 & 10 & 90 \\
\hline 24 & 140 & 650 & 17 & 5 & 90 \\
\hline 20 & 127 & 750 & 18 & 9,5 & 90 \\
\hline 19 & 120 & 825 & 12 & 6,7 & 90 \\
\hline 24 & 200 & 900 & 13 & 4,5 & 90 \\
\hline 22 & 150 & 650 & 17 & 8 & 90 \\
\hline 25 & 165 & 800 & 16 & 6,5 & 90 \\
\hline 20 & 175 & 540 & 12 & 7 & 90 \\
\hline 18 & 120 & 825 & 8 & 5 & 120 \\
\hline 19 & 200 & 700 & 9 & 4 & 120 \\
\hline 13 & 180 & 685 & 0 & 5,8 & 120 \\
\hline 16 & 180 & 750 & 6 & 3 & 120 \\
\hline 20 & 160 & 600 & 9 & 4,8 & 120 \\
\hline 18 & 190 & 785 & 8 & 3 & 120 \\
\hline 12 & 185 & 600 & 12 & 2,5 & 120 \\
\hline 17 & 155 & 800 & 11 & 5 & 120 \\
\hline 14 & 200 & 750 & 7 & 2,5 & 120 \\
\hline 15 & 125 & 725 & 9 & 4 & 120 \\
\hline 13 & 175 & 700 & 8 & 3,5 & 150 \\
\hline 15 & 165 & 787 & 12 & 1 & 150 \\
\hline 12 & 150 & 569 & 11 & 3 & 150 \\
\hline 14 & 200 & 854 & 15 & 1,5 & 150 \\
\hline 17 & 180 & 666 & 18 & 0,5 & 150 \\
\hline 12 & 125 & 550 & 16 & 2,5 & 150 \\
\hline 16 & 135 & 600 & 12 & 0,5 & 150 \\
\hline 15 & 125 & 550 & 8 & 1,8 & 150 \\
\hline 13 & 145 & 521 & 14 & 2 & 150 \\
\hline
\end{tabular}




\subsubsection{Analisis Statistik Deskriptif}

Berdasarkan dari hasil data yang diperoleh, data tersebut dilakukan uji deskriptif menggunakan Minitab 16. Berikut adalah hasilnya:

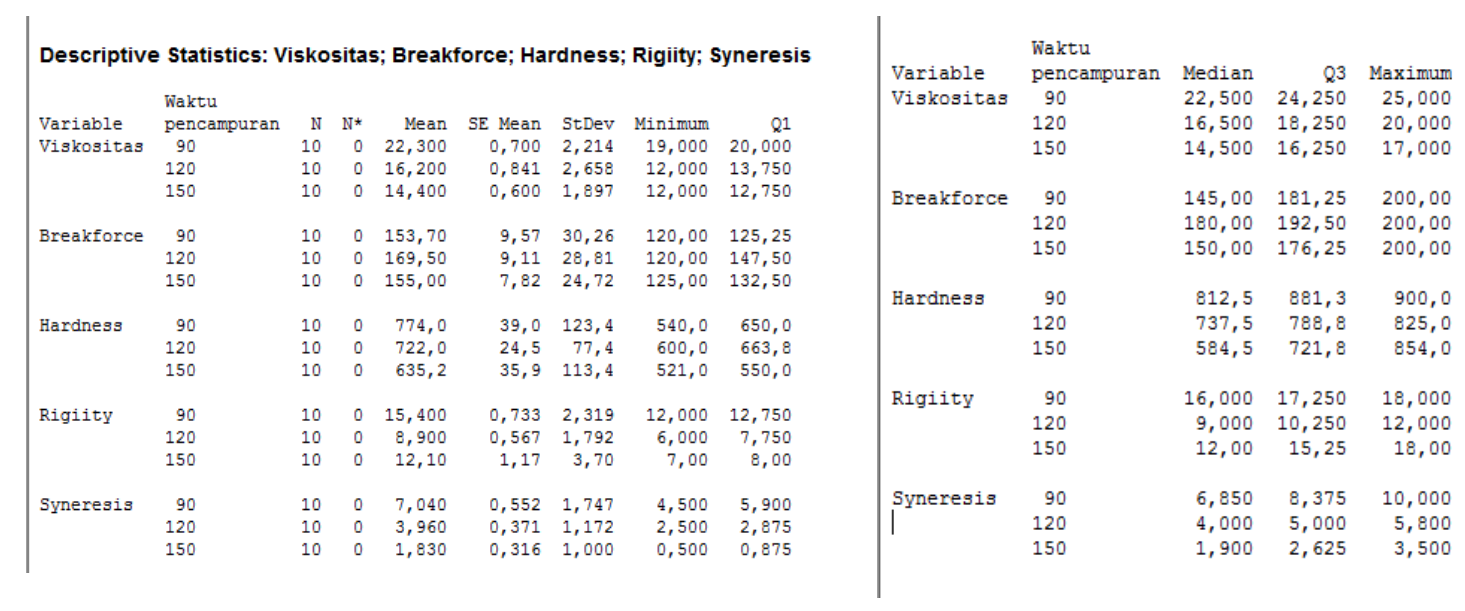

Gambar 3. Hasil Uji Statistik Deskriptif

Data pada Gambar 3 adalah data statistik deskriptif untuk hasil pengujian proses waktu pencampuran jelly powder A - 147 mengguankan minitab 16. Pada data tersebut dapat di ambil kesimpulan bahwa pada setiap pengambilan pada saat waktu pencampuran dengan jam yang brbeda menghasilkan variasi data yang berbeda.

\subsubsection{Analisis Uji Normalitas}

Dasar yang digunakan dalam pengambilan keputusan uji normalitas adalah:

Rumusan Hipotesis:

HO : Sample berasal dari populasi berdistribusi normal

H1 : Sample tidak berasal dari populasi berdistribusi normal

Dengan kriteria pengujian:

Jika $\mathrm{P}$ - Value $>\mathrm{a}=0,05$ terima $\mathrm{HO}$, dan

Jika $P$ - Value $<\alpha=0,05$ tolak $\mathrm{HO}$

Dan dibawah ini adalah hasil dari perhitungan normalitas pada Viskositas, Breakforce, Hardness, Rigidity, dan syneresis:

Tabel 7. Uji Normalitas

\begin{tabular}{|c|c|c|c|}
\hline NO & Nama Parameter & P-Value $(\alpha=0,05)$ & Keputusan \\
\hline 1 & Viskositas & 0,248 & H0 di terima \\
\hline 2 & Breakforce & 0,069 & H0 di terima \\
\hline 3 & Hardness & 0,220 & H0 di terima \\
\hline 4 & Rigidity & 0,093 & H0 di terima \\
\hline 5 & Sineresis & 0,422 & H0 di terima \\
\hline
\end{tabular}

Dari data di atas, kita mendapatkan bahwa data pada uji normalitas mempunyai sebaran yang normal. Terlihat dari hasil uji normalitas lima parameter bahwa $P$ - Value $>a=0,05$ sesuai dengan kriteria penerimaan. Ini menunjukkan bahwa HO di terima, karena sample berasal dari populasi berdistribusi Normal. 


\subsubsection{Uji Homogenitas}

Berikut ini adalah hasil uji homogenitas dengan kriteria pengujian sebagai berikut: Jika P- Value $>\mathrm{a}=0,05$ terima $\mathrm{HO}$, dan Jika $P$ - Value $<\mathrm{a}=0,05$ tolak $\mathrm{HO}$

Berikut adalah hasil uji homogenitas dari beberapa standar pengujian jelly powder A - 147 :

Tabel 8. Uji Homogenitas

\begin{tabular}{|c|c|c|c|}
\hline NO & Nama Parameter & P-Value $(\alpha=0,05)$ & Keputusan \\
\hline 1 & Viskositas & 0,471 & H0 di terima \\
\hline 2 & Breakforce & 0,815 & H0 di terima \\
\hline 3 & Hardness & 0,537 & H0 di terima \\
\hline 4 & Rigidity & 0,096 & H0 di terima \\
\hline 5 & Sineresis & 0,417 & H0 di terima \\
\hline
\end{tabular}

Dari hasil yang didapatkan pada Tabel 8 , pengujian homogenitas pada spesifikasi lima parameter mendapatkan hasil bahwa data tersebut homogen karena nilai P- Value pada uji barlett's test lebih besar dari $\mathrm{a}=0,05$, Sehingga $\mathrm{HO}$ di terima.

\subsubsection{Analisis of Variance (ANOVA)}

Anova satu jalur adalah analisis yang melibatkan hanya satu faktor. Dinamakan analisis varians satu arah menggunakan varians dan data hasil pengamatan dengan pengaruh satu faktor. Dari setiap populasi secara independen kita ambil sample secara acak. Berukuran $\mathrm{n}$ : dari populasi kesatu, $\mathrm{n}_{2}$ dari populasi kedua dan setereusnya sample berukuran $n_{k}$. Data sampel akan dinyatakan dengan $Y_{i j}$ yang berarti data ke-j dalam sampel yang diambil dari populasi ke-i. (Sudjana.1996). Pada pengujian anova satu arah ini, hanya mempunyai satu faktor yaitu "Waktu Pencampuran" dan 5 (lima) data pengujian yaitu: Viskositas, Hardness, Breakforce, Rigidity, dan Syneresis. Berikut adalah hasil uji anova dari Jelly Powder A - 147 :

Tabel 9. Uji Homogenitas

\begin{tabular}{|c|c|c|c|}
\hline NO & Nama Parameter & P-Value $(\alpha=0,05)$ & Keputusan \\
\hline 1 & Viskositas & 0,000 & H0 di tolak \\
\hline 2 & Breakforce & 0,389 & H0 di terima \\
\hline 3 & Hardness & 0,023 & H0 di tolak \\
\hline 4 & Rigidity & 0,000 & H0 di tolak \\
\hline 5 & Sineresis & 0,000 & H0 di tolak \\
\hline
\end{tabular}

Pada pengujian Anova One Way tabel 9, maka kita dapatkan analisis variansi $\mathrm{p}=0.000$. Terkait dengan data signifikasi $\alpha=0,05$, di peroleh $\mathrm{P}<\mathrm{a}$ berarti $\mathrm{HO}$ di tolak. Sehingga dapat di simpulkan bahwa tidak benar ketiga metode dengan perbedaan waktu pencampuran di jelly powder A - 147 memberikan efek yang sama untuk parameter (Viskositas, Hardness, Rigidity, dan Syneresis). Sedangkan Pada pengujian Anova One Way breakforce maka kita dapatkan analisis variansi $\mathrm{p}=0.389$. Terkait dengan data signifikasi $a=0,05$, di peroleh $P>a$ berarti HO diterima. Sehingga dapat di simpulkan bahwa benar ketiga metode dengan perbedaan waktu pencampuran di jelly powder A 147 memberikan efek yang sama.

\section{Kesimpulan}

1. Dua moda kegagalan yang menjadi penyebab utama produk reject Jelly Powder disebabkan oleh 4 elemen-elemen yaitu metode, manusia, material, dan lingkungan. Penyebabnya adalah tidak ada proses penimbangan ulang setelah proses grinding atau penghalusan, suhu ruang penyimpanan bahan baku dan ruang produksi yang kurang dikontrol sehingga menurunkan kualitas bahan baku, operator lalai dalam menjalankan instruksi kerja serta kurang pelatihan tentang kode bahan baku di Pabrik pangan, dan kurang ketatnya pengontrolan kualitas material (terutama ekstra rumput laut) dari supplier. Sehingga perlu dilakukan perbaikan dengan cara menambahkan instruksi kerja pada SOP, penambahan alat control suhu pada gudang bahan baku, 
melakukan training perihal sifat bahan baku, dan melalukan pencarian supplier dengan speksifikasi bahan baku yang sama.

2. Hasil pengujian optimalisasi waktu pencampuran produksi di 90 menit, 120 menit dan 150 menunjukkan bahwa nilai analisis dari 5 parameter Hardnes, Viskositas, Rigidity dan Syneresis adalah $\mathrm{p}<\mathrm{a}$ yaitu $\mathrm{P}=0,000-\mathrm{P}=0,023$ dari $\mathrm{a}=0,05$ sehingga $\mathrm{HO}$ ditolak, Sehingga $\mathrm{HO}$ di tolak dan dapat disimpulkan bahwa tidak benar ketiga metode tersebut dengan perbedaan waktu pencampuran pada jelly powder A - 147 yang memberikan efek yang sama. Tapi pada nilai $\mathrm{p}$ value Breakforce didapatkan nilai $P>$ a yaitu $P=0,389$. Namun jika bertuju pada pengurangan keluhan pelanggan pada bulan jul 2016 - jun 2017 maka waktu pencampuran di menit ke - 150 bisa di pakai karena rata - rata hasil nya mendekati dari standar pengujian jelly powder A - 147, karena pelanggan hanya mementingkan nilai Sineresis dan Hardness.

3. Didapatkan kombinasi treatment terbaik dalam mengoptimalisasi penggunaan fase gerak Metanol dalam analisa produk Hydroquinon adalah kombinasi treatment pada taraf kadar $60 \%$. Kombinasi ini didapat berdasarkan hasil pengujian ANOVA dua jalur dimana terdapat perbedaan yang signifikan pada kadar fase gerak yang digunakan, dan tidak terdapat perbedaan yang signifikan pada waktu pembuatan. Sehingga, dapat dipastikan kombinasi treatment terbaik dengan menggunakan kadar fase gerak sebesar $60 \%$ yang dapat menghasilkan nilai waktu Run Time yang sebentar.

4. Berdasarkan evaluasi diperoleh waktu terbaik untuk meminimalisasi biaya (cost) adalah per 4 minggu yang menghasilkan selisih cost yang memberikan minimalisasi sebesar Rp 336.668,dengan presentasi sebesar $43,32 \%$.

\section{Daftar Pustaka}

1. Boca Raton; 1983. Jurnal dalam Kuncari Emma Sri, Iskandarsyah dan Praptiwi. 2014 Evaluasi, Uji Stabilitas Fisik dan Sineresis Sediaan Gel Yang Mengandung Minoksidil, Apigenin dan Perasan Herba Seledri. Bul. Penelit. Kesehat, Vol. 42, No. 4.

2. Sudjana.1996. Metoda Statistika. Bandung:Tarsito Bandung.

3. Supratman, S. Herlina, H. 2017. Analysis of College Students's Difficulties in Mathematics Education of The Class 2013 in Sembilanbelas November University in Solving The Problem of One - Way Analysis of Variance (One Way Anova) on Applied Statistics Course. Jurnal of Mathematics Education, Vol. 2, November 2017.

4. Susanto Gunaedi, Rahardjo Jani. (2013). Perancangan Quality Plan Untuk Penurunan Tingkat Kecacatan Produk di PT. Sentosa Alloy Industri. Jurnal Titra. Vol 1 No.2, pp.135-140.

5. Zulian, Yamit. 2001. Manajemen Kualitas Produk dan Jasa. Yogyakarta: Ekonisia. 